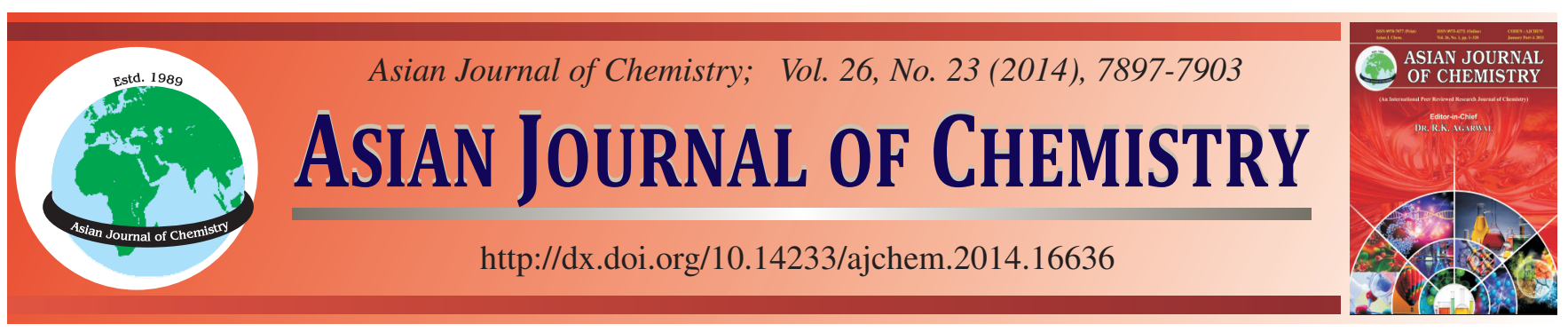

\title{
Purification of Total Polyphenols from Porphyra yezoensis
}

\author{
YINGCHANG $\operatorname{LI}^{1,2}$, YALI WANG $^{1,2}, \mathrm{JIANRONG} \mathrm{LI}^{1,2, *}$ and YiNG $\mathrm{CHEN}^{3}$
}

${ }^{1}$ College of Chemistry, Chemical Engineering and Food Safety, Bohai University, Jinzhou 121013, P.R. China

${ }^{2}$ Research Institute of Food Science, Bohai University, Jinzhou 121013, P.R. China

${ }^{3}$ Chinese Academy of Inspection and Quarantine, Beijing 100123, P.R. China

*Corresponding author: Tel: +86 416 3400302; E-mail: liyingchangsy@ sina.com, lijr6491@163.com

\begin{abstract}
Total polyphenols extracts from Porphyra yezoensis were pretreated in order to partially remove proteins and polysaccharides before purification by macroporous resins. The most appropriate resin was selected among 10 kinds of macroporous resins. Adsorption and desorption kinetics on AB-8 resins were determined by static adsorption and desorption experiments. The effect of polyphenols initial concentration, adsorption flow velocity, desorption flow velocity and the desorption solution concentration were investigated by using dynamic adsorption and desorption experiment. Polyphenols from Porphyra yezoensis was analyzed by HPLC-MS/MS. The results showed that AB-8 resin was most appropriate to purify total polyphenols, the adsorption capacity reached equilibrium after $4 \mathrm{~h}$, the desorption capacity reached equilibrium after $2 \mathrm{~h}$. The flow rate of absorption or desorption was $1 \mathrm{~mL} / \mathrm{min}$, the polyphenols solution concentration was $1 \mathrm{mg} / \mathrm{mL}$. The elution solvent was $90 \mathrm{~mL} 60 \%$ ethanol. The purity and recovery rate were 81.35 and $72.26 \%$, respectively. Seven kinds of polyphenols were separated and analyzed by HPLC-MS/MS.
\end{abstract}

Keywords: Porphyra yezoensis, Polyphenols, AB-8 macroporous resin, Adsorption, Desorption.

\section{INTRODUCTION}

Porphyra, belonging to R hodophyta, Bangiaceae plant group, is one of the most important economic algae. Porphyras in China are classified into Porphyra haitanensis $(P$. haitanensis.) and Porphyra yezoensis (P. yezoensis). P. yezoensis is commonly planted in China, Japan and South Korea. It has been reported that $P$. yezoensis has high proteins and low fat and be utilized as a source of important nutrients and functional ingredients. In recent years, polysaccharides and proteins from Porphyra have widely studied, but few researches regarding polyphenols from Porphyra have been reported.

Polyphenols are a class of chemical compounds in many flowers, vegetables and fruits, which are responsible for red, purple and blue colors. Many biochemical, epidemiological and pharmacological studies have reported that polyphenols of various crops are beneficial to human health, such as antioxidant activity, antibacterial, antiinflammatory, antiobesity, antidiabetes, antihypolipidemic effects, anticancer, apoptosis induction, improving memory and prevention of DNA damage ${ }^{1-8}$. Therefore, regular consumption of polyphenols rich foods has been considered to be associated with a reduction in the risk of developing chronic disease.
The purification of active constituents from plant extracts is an important step in the manufacture of phytochemical rich products. There are several methods, such as high-speed counter-current chromatography ${ }^{9}$, liquid-liquid extraction ${ }^{10}$ and ion exchange ${ }^{11}$ have been employed for the separation and purification of bioactive compounds from plant. However, these methods are high yielding cost, need longer time and more solvent consumption. Recently, macroporous resins, which are classified non-polar, middle polar and polar macroporous polymers ${ }^{12}$, have been successfully applied to separation and purification of bioactive components from many plant resources. The purification method of macroporous resins is high absorption capacity, low operating costs, low solvent consumption and easy regeneration ${ }^{13}$. The aim of this work is to investigate the adsorption and desorption properties of polyphenols on macroporous resins, to develop an efficient method for purification of total polyphenols from P. yezoensis.

\section{EXPERIMENTAL}

P. yezoensis were provided by Liaohai Food trade Co. (Dalian, China). Ethanol and petroleum ether were purchased from Tianli Chemical Reagent Co. (Tianjin, China). Gallic acid was obtained from Sigma Chemical Co. (St. Louis, USA). 
Folin-Ciocalteu reagent, sodium carbonate, glucose, sulphuric acid, phenol, bovine serum albumin (BSA), coomassie brilliant blue G-250, phosphoric acid, chlorform and $n$-butyl alcohol were obtained from Sinopharm Chemical Reagent Co. Ltd. (Shanghai, China). Macroporous resins including BS-8, BS30, BS-45, ADS-17, NKA-II, H1020, HZ-806, AB-8, HPD826 and J1were provided by Cangzhou the Bao En adsorption material Technology Co., Ltd.( Hebei, China). In order to remove the monomers and porogenic agents trapped inside the pores during synthesis process, the resins were pretreated by soaking in $95 \%$ ethanol for $24 \mathrm{~h}$. After removal of ethanol, the resins were washed by deionized water thoroughly. The moisture content of these resins was determined as follows: Three sample of each kind of macroporous resins were weighed and then placed in a drying oven at $110{ }^{\circ} \mathrm{C}$ until the mass did not change.

Preparation of total polyphenols extracts from $\boldsymbol{P}$. yezoensis: The $P$. yezoensis were dried at $50{ }^{\circ} \mathrm{C}$, crushed and sieved using a grinder and passed through a 100-mesh sieve. The extraction of polyphenols from $P$. yezoensis was carried out by Kazlowska et al. ${ }^{14}$ with slightly modifications. $100 \mathrm{~g}$ of dry coarse powder of $P$. yezoensis was added to $2.5 \mathrm{~L}$ of $70 \%$ $(\mathrm{v} / \mathrm{v})$ ethanol aiming to extract total polyphenols. Afterwards, the mixture was extracted in a water bath at $75{ }^{\circ} \mathrm{C}$ for $2.5 \mathrm{~h}$. Total polyphenols from $P$. yezoensis were filtered through filter paper, then concentrated by removing ethanol under reduced pressure in a rotary evaporator at $50{ }^{\circ} \mathrm{C}$. The concentrated extract was defatted with petroleum ether.

Determination of total polyphenols: Content of total polyphenols was determined by Folin-Ciocalteu colorimetric method described by Singleton and Rossi ${ }^{15}$ with some modifications. Briefly, $1 \mathrm{~mL}$ of measured solution and $1 \mathrm{~mL}$ of FolinCiocalteu reagent were mixed in $25 \mathrm{~mL}$ volumetric flask. After $8 \mathrm{~min}, 3 \mathrm{~mL}$ of $10 \%$ sodium carbonate solution was added and mixed thoroughly. The absorbance of the reaction mixtures was measured using spectrophotometer at $750 \mathrm{~nm}$ after incubation at $30^{\circ} \mathrm{C}$ for $1.5 \mathrm{~h}$. Calibration curves were established using a gallic acid standard in the range of $1-6 \mu \mathrm{g} / \mathrm{mL}$. The regression equation between gallic acid concentration $(\mu \mathrm{g} / \mathrm{mL})$ and absorbance value were obtained as $\mathrm{y}=0.1039 \mathrm{x}+0.008$ $\left(\mathrm{R}^{2}=0.9993\right)$, where $\mathrm{y}$ was the absorbance at $750 \mathrm{~nm}, \mathrm{x}$ was gallic acid concentration $(\mu \mathrm{g} / \mathrm{mL})$. The absorbance of polyphenols extract was also determined at $750 \mathrm{~nm}$. Polyphenols concentration was calculated according to the regression equation as above, then polyphenols content was calculated.

Removing proteins from polyphenols extracts before the purification of macroporous resins: Content of proteins was determined according to the method of Snyder and Deborough ${ }^{16}$. Proteins from polyphenols extracts were removed by the low speed centrifugation, isoelectric point ${ }^{17}$ method and Sevag method ${ }^{18}$.

$$
\text { Removing rate: } \mathrm{R}_{1}(\%)=\frac{\left(\mathrm{m}_{0}-\mathrm{m}_{1}\right)}{\mathrm{m}_{0}} \times 100
$$

where, $\mathrm{m}_{0}$ is the weight of proteins or polysaccharides in products before removing proteins or polysaccharides $(\mathrm{mg}), \mathrm{m}_{1}$ is the weight of proteins or polysaccharides in products after removing proteins or polysaccharides $(\mathrm{mg})$.

$$
\text { Retention rate: } \mathrm{R}_{2}(\%)=\frac{\mathrm{m}_{3}}{\mathrm{~m}_{2}} \times 100
$$

where, $\mathrm{m}_{2}$ is the weight of polyphenols in products before removing proteins or polysaccharides $(\mathrm{mg}), \mathrm{m}_{3}$ is the weight of polyphenols in products after removing proteins or polysaccharides (mg).

Precipitated polysaccharides from total polyphenols extracts: Content of polysaccharides was determined by the method of phenol to sulfuric acid ${ }^{19}$. The effect of ratio of ethanol to polysaccharide (v/v) (ethanol precipitation folds) and precipitated time was tested for removing polysaccharides from polyphenols extracts.

\section{Static adsorption and desorption experiments}

Screening macroporous resins: In order to get the most appropriate type of macroporous resins for enrichment of total polyphenols from $P$. yezoensis, ten different types of resins were tested. $1 \mathrm{~g}$ (dry weight) of pretreated macroporous resins and $50 \mathrm{~mL}$ of polyphenols solution were put into a $150 \mathrm{~mL}$ conical flask with stopper. The flasks were shaken on incubator (100 rpm) at $30^{\circ} \mathrm{C}$ for $24 \mathrm{~h}$ until the equilibrium reached. The content of total polyphenols in solution after adsorption was determined by Folin-ciocalteu method. After adsorption equilibrium reached, the resins were washed using distilled water, then desorbed with $50 \mathrm{~mL}$ of $60 \%$ ethanol solution in the conical flask shaken on incubator $(100 \mathrm{rpm})$ at $30{ }^{\circ} \mathrm{C}$ for $24 \mathrm{~h}$. The desorption solution was also determined by FolinCiocalteu method.

$$
\begin{gathered}
\text { Adsorption ratio: } \mathrm{A}(\%)=\frac{\left(\mathrm{C}_{0}-\mathrm{C}_{1}\right)}{\mathrm{C}_{0}} \times 100 \\
\text { Adsorption capacity: } \mathrm{q}_{\mathrm{e}}(\mathrm{mg} / \mathrm{g})=\frac{\left(\mathrm{C}_{0}-\mathrm{C}_{1}\right) \mathrm{V}_{1}}{(1-\mathrm{M}) \mathrm{W}}
\end{gathered}
$$

where, $\mathrm{A}$ is adsorption ratio $(\%)$ and $\mathrm{q}_{\mathrm{e}}$ is the adsorption capacity (mg/g dry resin) at adsorption equilibrium. $\mathrm{C}_{0}$ and $\mathrm{C}_{1}$ are the initial and equilibrium concentrations of total polyphenols, respectively $(\mathrm{mg} / \mathrm{mL})$. M is the moisture of macroporous resins $(\%), \mathrm{W}$ is the weight of macroporous resins used $(\mathrm{g}) . \mathrm{V}_{1}$ is the volume of total polyphenols solution $(\mathrm{mL})$.

$$
\begin{aligned}
& \text { Desorption ratio: } D(\%)=\frac{C_{2} \times V_{2}}{\left(C_{0}-C_{1}\right) V_{1}} \times 100 \\
& \text { Desorption capacity: } q_{d}(m g / g)=\frac{C_{2} \times V_{2}}{(1-M) W}
\end{aligned}
$$

where, $\mathrm{D}$ is desorption ratio $(\%)$ and $\mathrm{q}_{\mathrm{d}}$ is the desorption capacity (mg/g dry resin) until desorption equilibrium. $\mathrm{C}_{2}$ is the concentration of total polyphenols in the desorption solution $(\mathrm{mg} / \mathrm{mL}) . \mathrm{V}_{2}$ is the volume of the desorption solution $(\mathrm{mL})$.

Adsorption/desorption kinetics on AB-8 resins: To study the adsorption kinetics of AB- 8 macroporous resins, $1 \mathrm{~g}$ of pretreated macroporous resins and $50 \mathrm{~mL}$ of polyphenols solution were put into a $150 \mathrm{~mL}$ conical flask with stopper and then conical flasks were shaken on incubator (100 rpm) at $30{ }^{\circ} \mathrm{C}$. Total polyphenols concentration in the adsorption process at different time intervals until equilibration were determined. Completely adsorbed resins as above were desorbed 
by $50 \mathrm{~mL} 60 \%$ ethanol on shaker $(100 \mathrm{r} / \mathrm{min})$ at $30^{\circ} \mathrm{C}$. Concentration of total polyphenols in the desorption process were determined at different time intervals until equilibration.

Dynamic adsorption experiments: Dynamic adsorption tests were carried out on glass column $(1.5 \times 25 \mathrm{~cm})$. Different concentration polyphenols solution flowed through the glass column wet-packed with $10 \mathrm{~g}$ (dry weight) of AB-8 resins, separately. Polyphenols solution was determined after adsorption equilibration.

Effect of feeding flow rate and eluting flow rate: 120 $\mathrm{mL}$ of $1 \mathrm{mg} / \mathrm{mL}$ of total polyphenols flowed through the glass column at different flow rate to investigate the relationship between adsorption ratio and flow rate. After adsorption equilibrium, the absorbed was eluted by $60 \%$ ethanol solution at different flow rates to investigate the relationship between desorption ratio and flow rate.

Dynamic desorption experiments: To determine the optimum ethanol concentration for elution of the adsorbed polyphenols, the absorbed resins of polyphenols were eluted by different concentration ethanol solution. The contents of polyphenols in the elution solution were measured as described earlier.

The $60 \%$ ethanol solution was selected to elute AB-8 resins adsorbed polyphenols. The flow rate was $1 \mathrm{~mL} / \mathrm{min}$. Then, the dynamic desorption curve was drawn on the volume of desorption solution and the concentration of polyphenols.

Purity and recovery rate of total polyphenols: The eluted solution was collected and evaporated to remove the ethanol with a rotary evaporator under reduced pressure at $50{ }^{\circ} \mathrm{C}$. Concentrated solution was then followed by freezedrying using the freeze dryer. The purity and recovery rate were calculated.

$$
\text { Purity of equation as following: } \mathrm{p}(\%)=\frac{\mathrm{m}_{5}}{\mathrm{~m}_{4}} \times 100
$$

where $\mathrm{p}$ is the purity $(\%), \mathrm{m}_{4}$ is polyphenols content in products $(\mathrm{mg}), \mathrm{m}_{5}$ is the weight of products after purification by AB- 8 macroporous resins ( $\mathrm{mg}$ ).

The following equation was used to calculate recovery rate.

$$
\mathrm{r}(\%)=\frac{\mathrm{m}_{7}}{\mathrm{~m}_{6}} \times 100
$$

where $r$ is the recovery rate $(\%), \mathrm{m}_{6}$ is the weight of polyphenols before purification $(\mathrm{mg}), \mathrm{m}_{7}$ is the weight of polyphenols in products after purification $(\mathrm{mg})$.

Analysis of total polyphenols from $P$. yezoensis on HPLC-MS/MS: Analysis of $P$. yezoensis on HPLC-MS/MS was determined according to a method of Carazzone et al. ${ }^{20}$ with a little modification. Separations were performed on a Eclipse Plus $\mathrm{C}_{18}(4.6 \times 250 \mathrm{~mm}, 5 \mu \mathrm{m})$. The absorbance was measured at $280 \mathrm{~nm}$. The temperature of analysis was $25^{\circ} \mathrm{C}$. The injection volume was $10 \mu \mathrm{L}$. The total flow rate was 0.8 $\mathrm{mL} / \mathrm{min}$. The mobile phase consisted of (A) water $+0.1 \%$ formic acid and (B) methanol. A linear gradient program was used 010 min from 5 to $30 \%$ (B), 10-30 min 30-60\% (B), 30- 45 $\min 60-90 \%(\mathrm{~B})$ and then $45-50 \mathrm{~min} 90 \%$ (B). ESI-source parameters were as follows: Source voltage $4 \mathrm{kV}$, gas flow rate $8 \mathrm{~mL} / \mathrm{min}$, capillary voltage $4.5 \mathrm{KV}$, capillary temperature
$180{ }^{\circ} \mathrm{C}$. MS spectra were acquired by full range acquisition covering $50-3000 \mathrm{~m} / \mathrm{z}$.

\section{RESULTS AND DISCUSSION}

Comparison of different methods of removing proteins from total polyphenols extracts: As shown in Fig. 1, different methods of removing proteins ranked on the order of isoelectric point method $>$ Sevag method $>$ low-speed centrifugation. Removing rate of proteins by low-speed centrifugation was slightly lower than that the other two methods, but retention rate of polyphenols by the low speed centrifugation was highest among them. Chloroform was highly toxic reagent in Sevag method and was difficult to be applied in food, however there were not chemical reagents in low speed centrifugation and low speed centrifugation was safe, simple operation and low cost, so proteins were removed from polyphenols extracts by low-speed centrifugation.

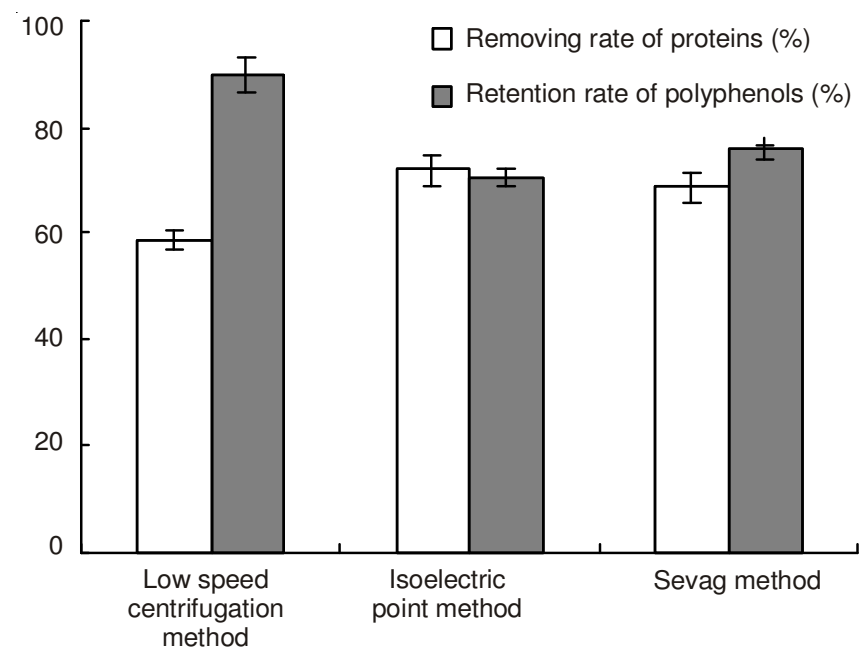

Fig. 1. Removing rate of proteins and retention rate of polyphenols by different treatments

Remove polysaccharides from polyphenols extracts by ethanol precipitation: As shown in Fig. 2a, removing rate of polysaccharides was increased with the increase of ethanol precipitation folds. The reason was that ethanol can make solubility of polysaccharides decreased and result in precipitation of polysaccharides when the concentration of ethanol was increased. While retention rate of polyphenols was decreased with the increase of ethanol precipitation folds because polyphenols was also partially precipitated with polysaccharides precipitation. Removing rate of polysaccharides had no significant difference among 6,7 and 8 folds and the retention rate of polyphenols was relatively high at 6 folds, so 6 folds of ethanol was selected.

As shown in Fig. 2b, removing rate of polysaccharides was first increased and then decreased with the increase of precipitation time. Polysaccharides were sufficiently precipitated with precipitation time extending, but polysaccharides could decompose into monosaccharides when precipitation time was too long. Retention rate of polyphenol was decreased with the increase of precipitation time owing to partly polyphenols precipitation. From considering removing rate of 

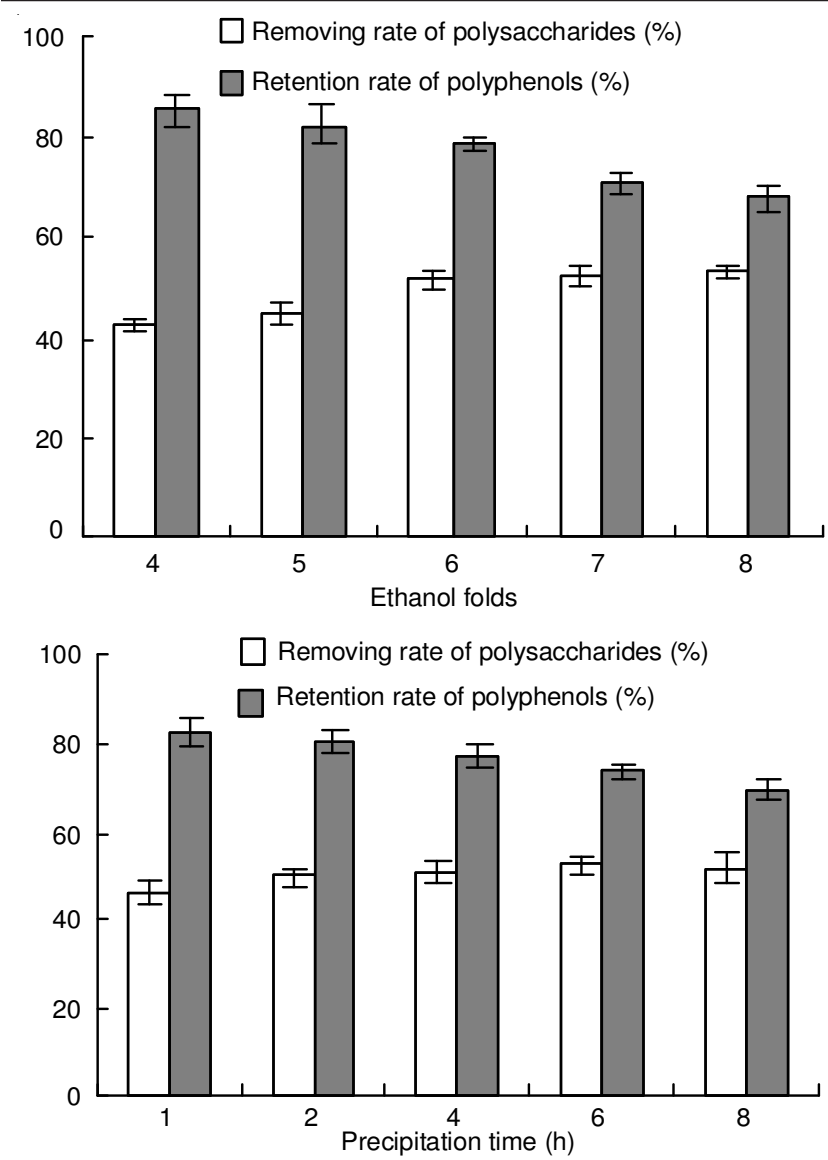

Fig. 2. (a) Effect of ethanol folds on removal rate of polysaccharide and retention rate of polyphenols (b) Effect of precipitation time on removal rate of polysaccharides and retention rate of polyphenols

polysaccharides and retention rate of polyphenols, $2 \mathrm{~h}$ of precipitation time was selected.

Screening macroporous resins: Ten macroporous resins with different physical properties were investigated for purification of total polyphenols from $P$. yezoensis. As shown in Table-1, the adsorption ratio of NKA-II and AB- 8 resins were higher than that of other resins. The desorption ratio of AB-8 resin was higher than other resins, but the desorption ratio of NKA-II resin was lower than AB-8 resin. The performance of macroporous resins was related to chemical features and physical properties of resins ${ }^{20}$. The selection of proper resins should be in accordance with polarities and structure, such as their pore sizes, surface areas. Resins which are lower polarity exhibit stronger adsorption abilities to low polarity and nonpolar substances. For example, NKA-II and AB-8 resins with low polarities had high adsorption capacities for polyphenols which are low polarity. In addition, the reason was attributed to $\pi$ - $\pi$ conjugation between polyphenols and benzene ring of resins, which was the main force in the adsorption of polyphenols on the resins. As AB- 8 resin had better adsorption and desorption properties, it was selected to purity polyphenols from $P$. yezoensis.

Adsorption/desorption kinetics on AB-8 resin: The adsorption kinetics of polyphenols curve was obtained, as shown in Fig. 3a. The adsorption capacity of polyphenols on AB-8 resin rapidly increased within $90 \mathrm{~min}$, then the adsorption capacity of total polyphenols on AB-8 resins slowly increased with the extension of adsorption time. Finally, the adsorption capacity reached equilibrium after $4 \mathrm{~h}$. The reason of this phenomenon was that high intra-particle mass transfer resistance existed in the process of polyphenols diffusing into the microspores of the resins. The desorption curve was as shown in Fig. 3b, the desorption capacity of polyphenols also rapidly elevate within $1 \mathrm{~h}$. The desorption capacity reached equilibrium after $2 \mathrm{~h}$. It showed that the process of desorption was very fast and effective using ethanol as eluted solution and the bonding force between resin and polyphenols was weaker than that between ethanol and polyphenols.

Effect of initial concentration of polyphenols: In order to characterize the adsorption behaviour of polyphenols on AB-8 resin, effect of initial concentration of polyphenols was investigated. The initial concentrations of polyphenols of polyphenols were $0.5,1,1.5$ and $2 \mathrm{mg} / \mathrm{mL}$, respectively. As shown in Fig. 4, the adsorption ratio of polyphenols was decreased with increasing of initial concentration of polyphenols. There was no significant difference in the adsorption ratio between initial concentration of $0.5 \mathrm{mg} / \mathrm{mL}$ and $1 \mathrm{mg} / \mathrm{mL}$, which showed $0.5 \mathrm{mg} / \mathrm{mL}$ and $1 \mathrm{mg} / \mathrm{mL}$ polyphenols was adsorbed completely by AB-8 resin. From considering full use of resins and polyphenols, thus $1 \mathrm{mg} / \mathrm{mL}$ of initial concentration of polyphenols was selected.

Effect of feeding and eluting flow rate: In the process of dynamic adsorption and desorption, flow rate is an important factor. Consequently, in order to obtain optimal experimental conditions, the effect of flow rate on adsorption and desorption

\begin{tabular}{|c|c|c|c|c|c|c|c|}
\hline \multicolumn{8}{|c|}{$\begin{array}{c}\text { TABLE-1 } \\
\text { PHYSICAL PROPERTIES AND RESULTS OF ADSORPTION RATIO AND } \\
\text { DESORPTION RATIO FOR DIFFERENT MACROPOROUS RESINS }\end{array}$} \\
\hline Resin series & Polarity & Partice size $(\mathrm{mm})$ & Surface area $\left(\mathrm{m}^{2} / \mathrm{g}\right)$ & Pore size $(\mathrm{nm})$ & $\begin{array}{c}\text { Moisture } \\
\text { content }(\%)\end{array}$ & $\begin{array}{c}\text { Adsorption } \\
\text { ratio }(\%)\end{array}$ & $\begin{array}{l}\text { Desorption } \\
\text { ratio }(\%)\end{array}$ \\
\hline BS-8 & Polar & $0.3-1.25$ & $100-120$ & $28-30$ & 67.6 & $20.53 \pm 0.60^{\mathrm{e}}$ & $56.53 \pm 3.01^{d}$ \\
\hline BS-30 & Polar & $0.3-1.25$ & $450-460$ & 8 & 62.8 & $9.93 \pm 0.55^{\mathrm{h}}$ & $72.13 \pm 3.15^{\mathrm{a}}$ \\
\hline BS-45 & Polar & $0.3-1.25$ & $450-500$ & $5-6$ & 65.6 & $15.2 \pm 0.56^{\mathrm{f}}$ & $56.47 \pm 3.39^{d}$ \\
\hline $\mathrm{J} 1$ & Polar & $0.3-1.25$ & - & $7-8$ & 63.5 & $19.70 \pm 0.55^{\mathrm{e}}$ & $65.83 \pm 4.02^{b c}$ \\
\hline ADS-17 & Mid-polar & $0.3-1.25$ & $90-150$ & $25-30$ & 55.6 & $23.53 \pm 0.40^{d}$ & $41.87 \pm 2.72^{\mathrm{e}}$ \\
\hline NKA-II & Polar & $0.3-1.25$ & $160-200$ & $14.5-15.5$ & 54.8 & $41.73 \pm 0.75^{\mathrm{a}}$ & $33.17 \pm 1.50^{f}$ \\
\hline H1020 & Non-polar & $0.3-1.25$ & - & - & 50.7 & $27.40 \pm 0.62^{c}$ & $45.73 \pm 2.63^{\mathrm{e}}$ \\
\hline HZ-806 & Mid-polar & $0.3-1.25$ & - & - & 70.2 & $16.13 \pm 0.51^{\mathrm{f}}$ & $64.27 \pm 1.48^{c}$ \\
\hline AB-8 & Weak-polar & $0.3-1.25$ & $480-520$ & $13-14$ & 72.5 & $40.40 \pm 0.82^{b}$ & $70.7 \pm 1.64^{\mathrm{ab}}$ \\
\hline HPD826 & Polar & $0.3-1.25$ & $500-600$ & $9-10$ & 68.9 & $13.83 \pm 0.31^{\mathrm{g}}$ & $62.13 \pm 4.10^{c}$ \\
\hline
\end{tabular}



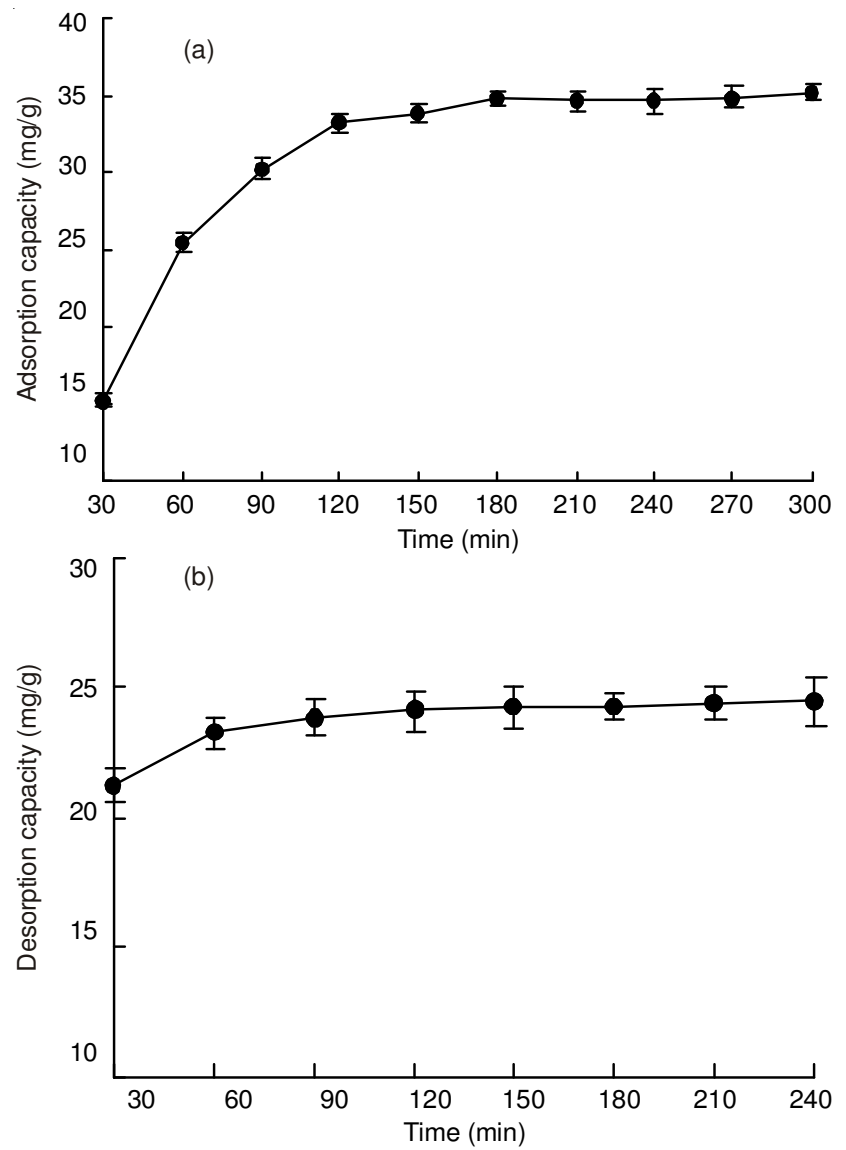

Fig. 3. (a) Adsorption kinetics curves of polyphenols on AB-8 resin (b) Desorption kinetics curves of polyphenols on AB-8 resin

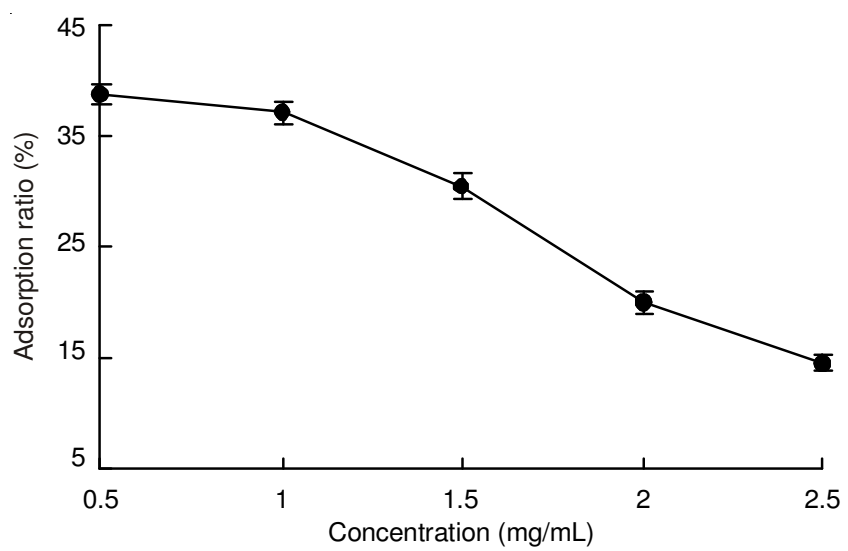

Fig. 4. Effect of initial concentration of polyphenols on adsorption

ratio was investigated. As shown in Fig. 5a, the decrease of adsorption ratio of polyphenols was observed with the increase of flow rate. In general, increasing flow rate of adsorption has a negative effect on dynamic adsorption because absorbate molecules have no sufficient time to undergo interactions with active sites at the surface of resins ${ }^{21}$. Hence, when the flow rate was faster, the contact time between polyphenols molecules and the resins was shorter, leading to incomplete adsorption. A portion of polyphenols leaked without being adsorbed by AB-8 resin when flow rate was 1.5 and $2.0 \mathrm{~mL} /$ min. Taking adsorption ratio and productivity effect into consideration, $1 \mathrm{~mL} / \mathrm{min}$ of flow rate on adsorption was selected. As shown in Fig. 5b, desorption ratio was decreased with the increase of flow rate on desorption. Similarly, when
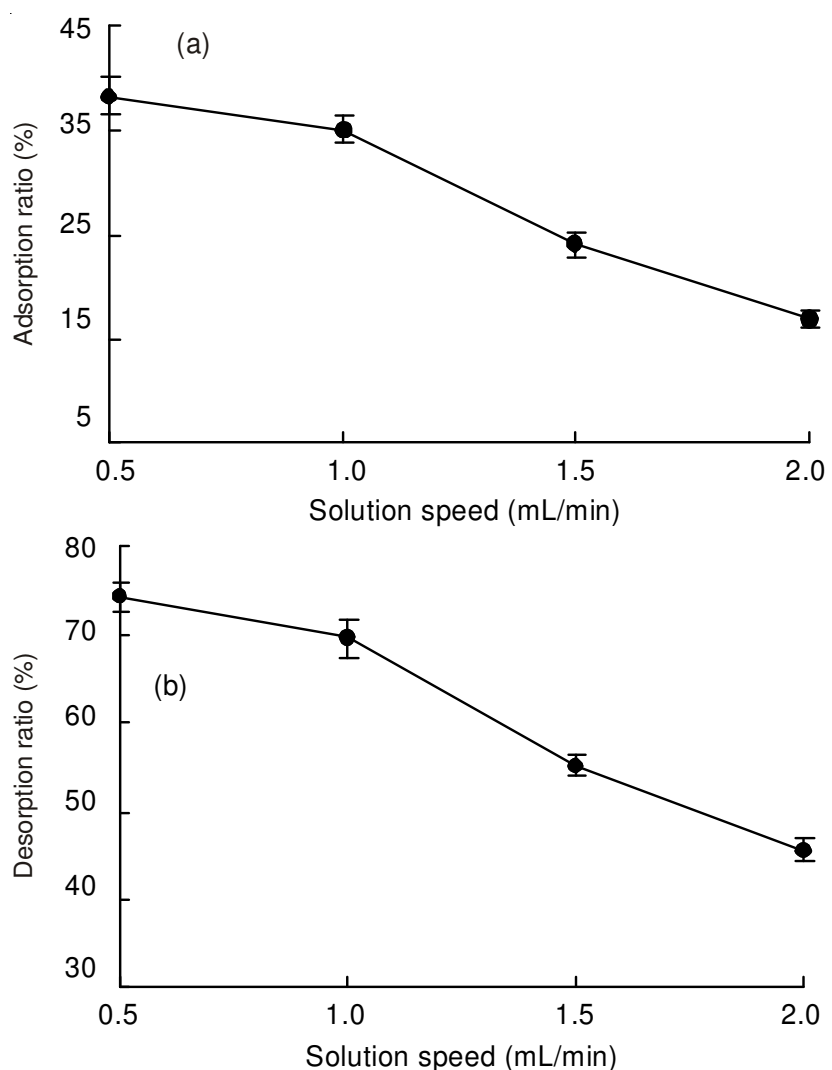

Fig. 5 (a) Effect of the solution speed on adsorption (b) Effect of the solution speed on desorption

flow rate was faster, the contact time between the polyphenols on resins and elute liquid was shorter and parts of elute liquid effused directly without eluting the AB-8 resin sufficiently, so desorption ratio was decreased. There was not significantly difference $(\mathrm{P}>0.05)$ between $0.5 \mathrm{~mL} / \mathrm{min}$ and $1 \mathrm{~mL} / \mathrm{min}$ on desorption ratio. When flow rate was over $1 \mathrm{~mL} / \mathrm{min}$, desorption ratio was significantly decreased $(\mathrm{P}<0.05) .1 \mathrm{~mL} / \mathrm{min}$ of flow rate was selected on desorption.

Effect of ethanol concentration of elute liquid: Ethanol solutions of different concentration were examined in order to select proper desorption solution. The result of the elution test was shown in Fig. 6. The desorption ratio of polyphenols was increased with the increase of ethanol concentration and was highest at $60 \%$ ethanol,then decreased. At the same time, the impurities desorbed were increased when the concentration

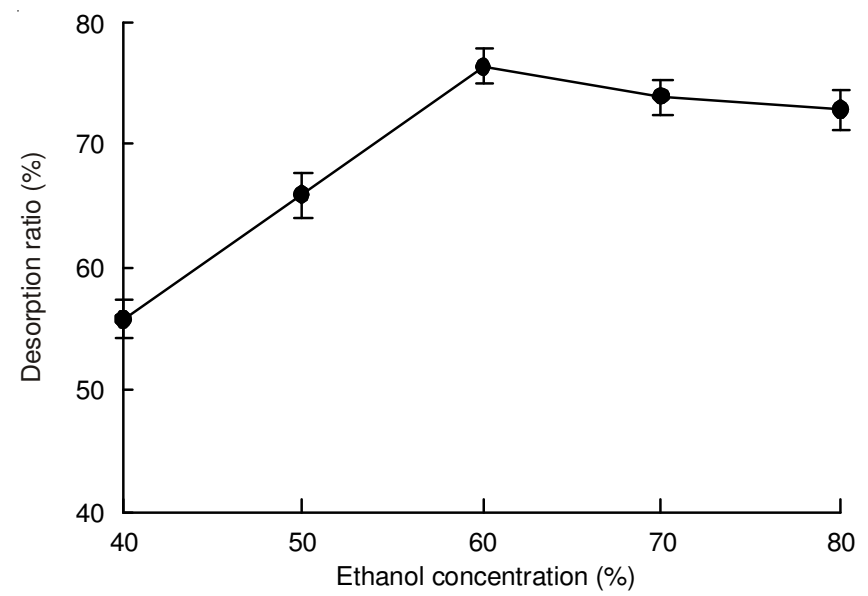

Fig. 6. Effect of ethanol concentration on desorption 
of ethanol exceeded $60 \%$. After the comprehensive consideration, $60 \%(\mathrm{v} / \mathrm{v})$ ethanol was selected as the appropriate desorption solution.

Dynamic desorption curve on AB-8 resin: The dynamic desorption curves on $\mathrm{AB}-8$ resin were obtained with the volume of desorption solution and the polyphenols concentration of desorption solution. As shown in Fig. 7, polyphenols adsorbed by AB- 8 resins were desorbed by $60 \%$ ethanol. Polyphenols concentration was highest when desorption solution was $30 \mathrm{~mL}$. Polyphenols could be completely desorbed by approximately $100 \mathrm{~mL}$ of desorption solution.

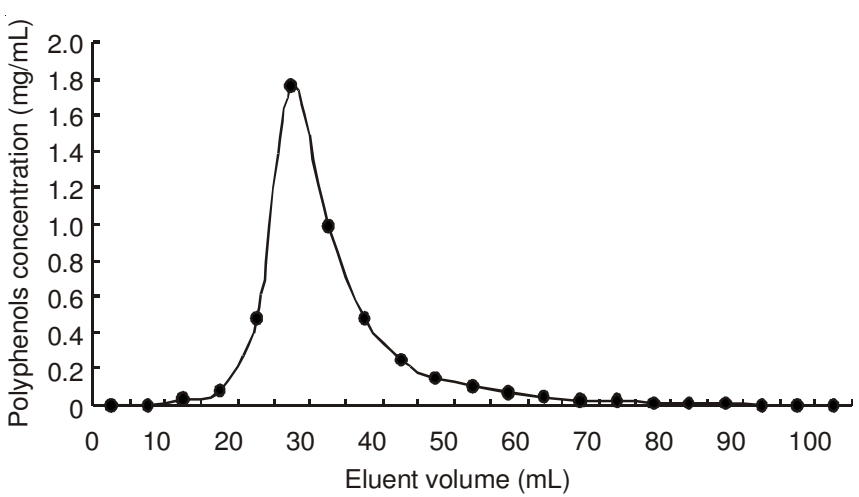

Fig. 7. Curve of eluent of polyphenols

Purity and recovery rate of polyphenols: The eluated solutions were collected and evaporated to remove the ethanol with a rotary evaporator under reduced pressure at $50{ }^{\circ} \mathrm{C}$. Concentrated solutions were then followed by freeze-drying using the freeze dryer. After treatment with AB- 8 resins, the purityof polyphenols was $81.35 \%$ and recovery rate was $72.26 \%$

Analysis of polyphenolics from $P$. yezoensis by HPLCESI/MS: The chromatogram of total polyphenols after treatment with AB-8 resins was shown in Figs. 8 and 9, Seven polyphenolic compounds were separated by HPLC. Polyphenols are phytochemicals which show wide structural varieties. In the absence of standards, the identification of the corresponding compound was based on the search for the [M$\mathrm{H}$ ] deprotonated molecule together with the interpretation of its fragmentations. The exact mass search and the study of the fragmentation pathways described in the literature enabled us to obtain as much structural information as possible. As shown Table-2, Peak 1, with an [M-H] $]^{-}$at $m / z, 333$, produced the $\mathrm{MS}^{2}$

TABLE-2

MASS SPECTRAL DATA OF THE MAJOR COMPONENTS IN POLYPHENOLS FROM Porphyra yezoensis

\begin{tabular}{|c|c|c|c|c|}
\hline No. & $\begin{array}{l}\text { Retention } \\
\text { time/min }\end{array}$ & $\begin{array}{c}\mathrm{MS} \\
(\mathrm{m} / z)\end{array}$ & MS-MS $(m / z)$ & Tentative identification \\
\hline 1 & 4.1 & 333.1 & $333.1,318.1,303.1$ & Gallic acid-glucose \\
\hline 2 & 5.0 & 347.1 & $332.1,314.1,303.1$ & Unknown \\
\hline 3 & 8.2 & 363.2 & $347.2,312.2$ & $\begin{array}{l}\text { Dimethoxycinnamoyl } \\
\text { shikimic acid }\end{array}$ \\
\hline 4 & 8.8 & 569 & 487.6 & Unknown \\
\hline 5 & 11.8 & 348.0 & $347.0,318.1,288.6$ & Unknown \\
\hline 6 & 15.6 & 556.0 & 435.1 & $\begin{array}{c}\text { Delphinidin 3-O- } \\
\text { arabinoside derivative }\end{array}$ \\
\hline 7 & 19.6 & 377.1 & $359.1,316.1$ & $\begin{array}{c}\text { Oleuropein aglycone } \\
\text { derivative }\end{array}$ \\
\hline
\end{tabular}

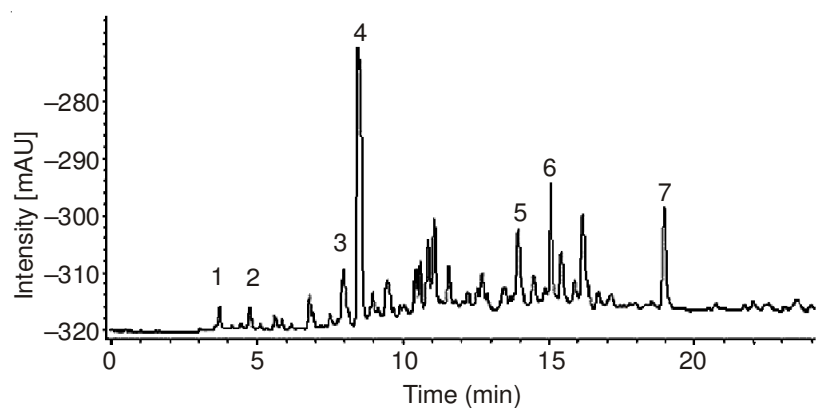

Fig. 8. HPLC chromatogram of polyphenols from Porphyra

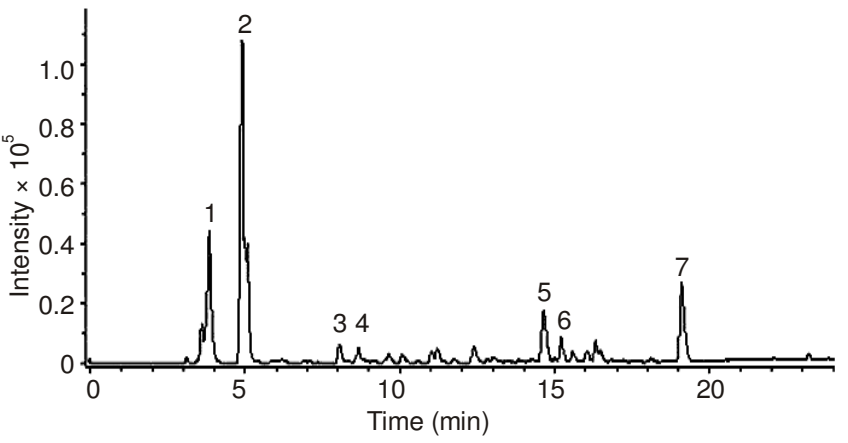

Fig. 9. Total ion chromatogram (TIC) of polyphenols from Porphyra

base peak at $m / z 303.1$ and was assigned to gallic acid-glucose $\mathrm{e}^{22}$. Peak 3, with an [M-H] $]^{-}$at $m / z, 363$, with MS $^{2}$ fragments at $m / z$ 347 and at $m / z$ 312, was identified as dimethoxyc-innamoyl shikimic acid ${ }^{23}$. Peak 6 was identified as delphinidin 3-Oarabinoside derivative (MS 556) due to the $\mathrm{MS}^{2}$ base peak at $m / z 435.1^{24}$. The derivatives of Oleuropein aglycone derivative was identified by comparison with the literature ${ }^{25}$. Compounds of peak 2, peak 4 and peak 5 were unknown.

\section{Conclusion}

AB-8 resin was a suitable resin for purification polyphenols because of its higher adsorption and desorption ratio. During adsorption/ desorption kinetics on AB-8 resins, when the adsorption/desorption capacity reached equilibrium, time was $4 \mathrm{~h}$ and $2 \mathrm{~h}$, separately. From the dynamic adsorption and desorption experiments through column packed with AB-8 resin, the best separation conditions were obtained as follows: The concentration of polyphenols was $1 \mathrm{mg} / \mathrm{mL}$. Adsorption and desorption flow rate were $1 \mathrm{~mL} / \mathrm{min}$, respectively. The elution solvent was $90 \mathrm{~mL} 60 \%$ ethanol. The purity and recovery rate were 81.35 and $72.26 \%$, respectively. In conclusion, this method could be used in large-scale production of purification polyphenols from $P$. yezoensis in industry, owing to the prominent advantages of macroporous resins such as procedural simplicity, low cost, higher purification efficiency and easier scale-up.

\section{ACKNOWLEDGEMENTS}

This work was supported by the National Natural Science Fund (No. 31201308 ), the Specialized Research Fund on Priority Area for the Doctoral Program of Higher Education of China (No. 20113326130001), a grant from the National Key Technologies R \& D Program of China during 12th FiveYear Plan Period (No. 2012BAD29B06), Open Foundation of Food Safety Key Laboratory of Liaoning Province and 
Engineering and Technology Research Center of Food Preservation, Processing and Safety Control of Liaoning Province (No. LNSAKF2011016).

\section{REFERENCES}

1. L. Boulekbache-Makhlouf, S. Slimani and K. Madani, Ind. Crops Prod., 41, 85 (2013).

2. K. Kazlowska, T. Hsu, C.-C. Hou, W.-C. Yang and G.-J. Tsai, J. Ethnopharmacol., 128, 123 (2010).

3. T. Sergent, J. Vanderstraeten, J. Winand, P. Beguin and Y.J. Schneider, Food Chem., 135, 68 (2012).

4. R. Li, T. Liang, L.Y. Xu, Y. Li, S. Zhang and X. Duan, Food Chem. Toxicol., 51, 419 (2013).

5. R.R. Bansode, P. Randolph, S. Hurley and M. Ahmedna, Food Chem., 135, 1659 (2012).

6. F. Nwosu, J. Morris, V.A. Lund, D. Stewart, H.A. Ross and G.J McDougall, Food Chem., 126, 1006 (2011).

7. D.H. Malin, D.R. Lee, P. Goyarzu, Y.H. Chang, L.J. Ennis, E. Beckett, B. Shukitt-Hale and J.A. Joseph, Nutr., 27, 338 (2011).

8. M.C. Lazzé, R. Pizzala, M. Savio, L.A. Stivala, E. Prosperi and L. Bianchi, Mutat. Res.-Gen. Tox. En., 535, 103 (2003).

9. D.G. Wang, W.Y. Liu and G.T. Chen, J. Pharm. Anal., 3, 241 (2013).

10. H.Y. Cui, X.Y. Jia, X. Zhang, J. Zhang and Z.Q. Zhang, Sep. Purif. Technol., 77, 269 (2011).
11. N. Skelly and W. Crummett, J. Chromatogr. A, 55, 309 (1971).

12. Y. Zhang, S.F. Li, X.W. Wu and X. Zhao, Chin. J. Chem., 15, 872 (2007).

13. X.L. Du, Q.P. Yuan, Y. Li and H.H. Zhou, Chem. Eng. Technol., 31, 87 (2008).

14. K. Kazlowska, T. Hsu, C.-C. Hou, W.-C. Yang and G.-J. Tsai, J. Ethnopharmacol., 128, 123 (2010).

15. V.L. Singleton and J.A. Rossi, Am. J. Enol. Vitic., 16, 144 (1965).

16. J.C. Snyder and S.L. Desborough, Theor. Appl. Genet., 52, 135 (1978).

17. X.Y. Dong, L.L. Guo, F. Wei, J.F. Li, M.L. Jiang, G.M. Li, Y.D. Zhao and H. Chen, J. Sci. Food Agric., 91, 1488 (2011).

18. A.M. Staub, Methods in Carbohydrate Chem., 5, 5 (1965).

19. M. Dubois, K.A. Gilles, J.K. Hamilton, P.A. Rebers and F. Smith, Anal. Chem., 28, 350 (1956).

20. C. Carazzone, D. Mascherpa, G. Gazzani and A. Papetti, Food Chem., 138, 1062 (2013).

21. C. Ma, G. Tao, JianTang, Z. Lou, H. Wang, X. Gu, L. Hu and M. Yin, Sep. Purif. Technol., 69, 22 (2009).

22. K.W. Kang, S.J. Oh, S.Y. Ryu, G.Y. Song, B.H. Kim, J.S. Kang and S.K. Kim, Food Chem., 121, 1089 (2010).

23. C. Carazzone, D. Mascherpa, G. Gazzani and A. Papetti, Food Chem., 138, 1062 (2013).

24. M.C. Díaz-García, J.M. Obón, M.R. Castellar, J. Collado and M. Alacid, Food Chem., 138, 938 (2013).

25. A. Rameshkumar, T. Sivasudha, R. Jeyadevi, B. Sangeetha, G. Smilin Bell Aseervatham and M. Maheshwari, Food Res. Int., 50, 94 (2013). 